\title{
Physical and thermal properties of mud-dominant sediment from the Joetsu Basin in the eastern margin of the Japan Sea
}

\author{
Shusaku Goto ${ }^{1}$ (D) Makoto Yamano ${ }^{2}$ Sumito Morita ${ }^{1}$ - Toshiya Kanamatsu ${ }^{3}$. \\ Akihiro Hachikubo $^{4} \cdot$ Satsuki Kataoka $^{5} \cdot$ Manabu Tanahashi $^{6} \cdot$ Ryo Matsumoto $^{6}$
}

Received: 24 November 2016 / Accepted: 16 January 2017 / Published online: 26 May 2017

(c) The Author(s) 2017. This article is an open access publication

\begin{abstract}
Physical properties (bulk density and porosity) and thermal properties (thermal conductivity, heat capacity, specific heat, and thermal diffusivity) of sediment are crucial parameters for basin modeling. We measured these physical and thermal properties for mud-dominant sediment recovered from the Joetsu Basin, in the eastern margin of the Japan Sea. To determine thermal conductivity, heat capacity, and thermal diffusivity, the dual-needle probe method was applied. Grain density and grain thermal properties for the mud-dominant sediment were estimated from the measured physical and thermal properties by applying existing models of physical and thermal properties of sediment. We suggest that the grain density, grain thermal conductivity, and grain thermal diffusivity depend
\end{abstract}

Shusaku Goto

s.gotou@aist.go.jp

1 Research Institute for Geo-Resources and Environment, National Institute of Advanced Industrial Science and Technology, AIST Tsukuba Central 7, 1-1-1 Higashi, Tsukuba, Ibaraki 305-8567, Japan

2 Earthquake Research Institute, The University of Tokyo, 1-1-1 Yayoi, Bunkyo-ku, Tokyo 113-0032, Japan

3 Research and Development Center for Earthquake and Tsunami, Japan Agency for Marine-Earth Science and Technology, 2-15 Natsushima-cho, Yokosuka, Kanagawa 237-0061, Japan

4 Environmental and Energy Resources Research Center, Kitami Institute of Technology, 165 Koen-cho, Kitami, Hokkaido 090-8507, Japan

5 Department of Civil Engineering, Kobe University, 1-1 Rokkodai-cho, Nada-ku, Kobe, Hyogo 657-8501, Japan

6 Gas Hydrate Research Laboratory, Organization for the Strategic Coordination of Research and Intellectual Properties, Meiji University, 1-1 Kanda-Surugadai, Chiyoda-ku, Tokyo 101-8301, Japan on the sediment mineral composition. Conversely, the grain heat capacity and grain specific heat showed hardly any dependency on the mineral composition. We propose empirical formulae for the relationships between: thermal diffusivity and thermal conductivity, and heat capacity and thermal conductivity for the sediment in the Joetsu Basin. These relationships are different from those for mud-dominant sediment in the eastern flank of the Juan de Fuca Ridge presented in previous work, suggesting a difference in mineral composition, probably mainly in the amount of quartz, between the sediments in that area and the Joetsu Basin. Similar studies in several areas of sediments with various mineral compositions would enhance knowledge of the influence of mineral composition.

Keywords Thermal conductivity · Thermal diffusivity · Heat capacity $\cdot$ Specific heat $\cdot$ Dual-needle probe method . Mineral composition

\section{Introduction}

Thermal properties (thermal conductivity, heat capacity, specific heat, and thermal diffusivity) of marine sediment are important parameters for estimating the flow of fluid and heat in sediment and modeling thermal structure below the seafloor. The thermal conductivity of marine sediment in particular is crucial for calculating heat flow, which provides fundamental information on the thermal state below the seafloor. Simple methods have been developed for measuring the thermal conductivity of marine sediment, using a single-needle probe (Von Herzen and Maxwell 1959) and a half-space box-type probe (Sass et al. 1984). Using these methods, many thermal conductivity data on marine sediment have been accumulated. 
In addition, the thermal conductivity of marine sediment has been predicted from its mineral composition. This has been performed using the relationship between the thermal conductivity of marine sediment and the porosity and volume fraction of the constituent minerals of the sediment (Kinoshita 1994; Villinger et al. 1994; Goto and Matsubayashi 2009).

Compared with the works on thermal conductivity, there are relatively few studies on heat capacity, specific heat, and thermal diffusivity of marine sediment. The relationship between thermal conductivity $K_{s}$, heat capacity $\rho_{s} c_{s}$ (bulk density $\rho_{s}$ and specific heat $c_{s}$ ), and thermal diffusivity $\kappa_{s}$ is given by

$\kappa_{s}=\frac{K_{s}}{\rho_{s} c_{s}}$

Kinoshita et al. (1996) and Hamamoto et al. (2005) estimated the thermal diffusivity of marine sediment near the seafloor from the thermal response of the sediment to bottom-water temperature variation. Goto and Matsubayashi (2008) developed a method for measuring thermal conductivity and heat capacity of sediment using a single-needle probe. Using this method, they estimated the thermal conductivity and heat capacity (and hence thermal diffusivity) of marine sediment recovered at the eastern flank of the Juan de Fuca Ridge. Lin et al. (2014) determined thermal conductivity, heat capacity, and thermal diffusivity of core samples obtained from the Japan Trench by applying the hot-disk method (Gustafsson 1991). Applying the same method, Tanikawa et al. (2016) determined these three properties for core samples taken from the sedimentary basin off Shimokita, Japan. Empirical formulae connecting heat capacity and thermal diffusivity to thermal conductivity for marine sediment were developed to infer heat capacity and thermal diffusivity from existing thermal conductivity data for the sediment (Von Herzen and Maxwell 1959; Hyndman et al. 1979; Goto and Matsubayashi 2008). Goto and Matsubayashi (2009) investigated the relationship of thermal properties (heat capacity, specific heat, and thermal diffusivity) with the volume fractions of the component minerals of the marine sediment recovered from the eastern flank of the Juan de Fuca Ridge to calculate their thermal properties. However, because of the limited number of direct measurements of these properties, the thermal properties of marine sediments remain poorly understood.

The Joetsu Basin, in the eastern margin of the Japan Sea, is characterized by a methane venting system associated with gas hydrate in sediment near the seafloor (Matsumoto et al. 2009). In June 2010, the MD179 research cruise using the French R/V Marion Dufresne was conducted to investigate gas hydrate formation mechanisms in sediment of relatively shallow depth below the seafloor of the Joetsu Basin. During the cruise, heat flow data were obtained by measuring geothermal gradients and thermal conductivities to investigate the gas hydrate formation process and to establish a thermal structure model of the basin. Geothermal gradients were measured by inserting a geothermal probe with temperature loggers into the sediment. We determined heat capacity and thermal diffusivity, together with thermal conductivity, of the sediment from core samples recovered from the seafloor, by applying the dual-needle probe method (Bristow 1998), described in detail in the "Dual-needle probe method "section below. Physical properties (porosity and bulk density) of the sediment were measured during onshore-based studies to obtain basic information about the sediment.

We present the results of our measurements of thermal properties and physical properties of mud-dominant sediment recovered from the seafloor of the Joetsu Basin. Using these results, we examine grain density and grain thermal properties of the sediment from the measured physical and thermal properties of the sediment. Finally, we investigate the relationships between thermal conductivity and thermal diffusivity, and thermal conductivity and heat capacity, of the sediment.

\section{Geologic setting}

The Joetsu Basin (Fig. 1), with a water depth of 900-1300 m, lies between Toyama Bay and Sado Island, on the eastern margin of the Japan Sea. Sediment near the seafloor of the basin is composed mainly of hemipelagic silty clay, including thin layers of ash and turbidite sands (Katayama et al. 1994; Hiruta et al. 2009; Kakuwa et al. 2013a, b). Because this basin is located west of one of the oil-gas fields along the coast of the Japan Sea, it is expected that the basin is potentially rich in fuel resources (Osawa et al. 2005; Monzawa et al. 2006).

The Joetsu Basin is characterized by two major bathymetric features formed by asymmetric anticline structures: one is a spur that protrudes from the continental slope, called the Umitaka Spur and the other is an isolated NE-SW trending knoll, named the Joetsu Knoll, located northwest of the Umitaka Spur (Fig. 1). Mounds and pockmarks, $50-100 \mathrm{~m}$ in diameter, show a linear distribution pattern that is parallel to the axis on the top of the Umitaka Spur and the Joetsu Knoll (Matsumoto et al. 2011; Nakajima et al. 2014). Two- and three-dimensional seismic data obtained from the Umitaka Spur identified seismic blanking that obscured reflectors beneath the mounds and pockmarks, suggesting subsurface gas migration from deep (Saeki et al. 2009; Freire et al. 2011). Active cold-seep sites 


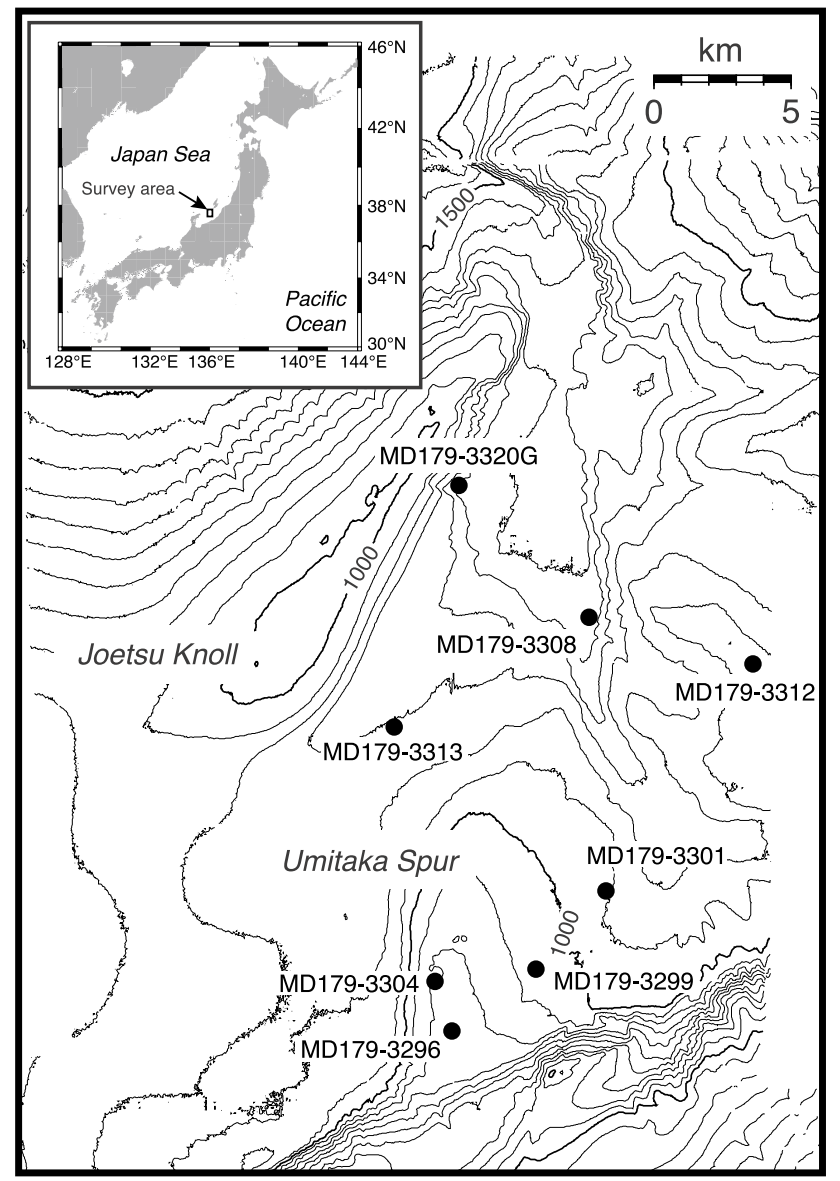

Fig. 1 Bathymetric map of the Joetsu Basin at the eastern margin of the Japan Sea. Bathymetric data from Hiromatsu et al. (2011). Eight sampling stations where the physical and thermal properties of sediments were measured are indicated. The inset shows the location of the study area

with biological communities were discovered on several mounds at the summit areas of the Umitaka Spur and the Joetsu Knoll. In these mounds, exposures of gas hydrate and active seeps of methane gas at the seafloor were observed (Matsumoto et al. 2009; Aoyama and Matsumoto 2009).

\section{Dual-needle probe method}

In this study, thermal conductivity, heat capacity, and hence thermal diffusivity of marine sediment were determined by applying the dual-needle probe method (Bristow 1998), which is based on theory that expresses the thermal response of a medium at the radial distance $r$ from an infinite linear heat source heated at a constant rate in the medium. In this method, a sensor with two thin, parallel, metallic needles at a spacing of several millimeters is used. One needle contains a heater line and the other a thermistor. First, the needles of the sensor are inserted into the material. When the temperature of the needles is equal to that of the material, the needle with the heater line starts heating at a constant rate for a given length of time. A thermistor inside the other needle measures the change in temperature of the material at that point in response to the heating operation of the needle with the heater line. Thermal conductivity and heat capacity (or thermal diffusivity) of the material are determined simultaneously from the measured temperature change. Another thermal property (heat capacity or thermal diffusivity) is calculated from the two measured thermal properties. The advantage of this method is that it determines three thermal properties simultaneously, although the measurement process is almost the same as that for a single-needle probe.

We assume that an infinite linear heat source is in an infinite, seawater-saturated, sediment with thermal conductivity $K_{s}$ and heat capacity $\rho_{s} c_{s}$. Initially, the temperatures of both the line heat source and the sediment are zero. We start heating the line heat source at a constant rate $q$ per unit length and unit time at time $t=0$ and then stop heating at $t=t_{0}$. The temporal change in temperature of the sediment at radial distance $r$ from the line heat source is expressed as (de Vries 1952; Carslaw and Jaeger 1959)

$T(t)=-\frac{q}{4 \pi K_{s}} E i\left[-\frac{r^{2}}{4 t\left(\frac{K_{s}}{\rho_{s} c_{s}}\right)}\right]\left(0<t \leq t_{0}\right)$

and

$T(t)=-\frac{q}{4 \pi K_{s}}\left\{E i\left[-\frac{r^{2}}{4 t\left(\frac{K_{s}}{\rho_{s} c_{s}}\right)}\right]-E i\left[-\frac{r^{2}}{4\left(t-t_{0}\right)\left(\frac{K_{s}}{\rho_{s} c_{s}}\right)}\right]\right\} \quad\left(t>t_{0}\right)$,

where the function $-E i(-x)$ is the exponential integral defined as

$-E i(-x)=\int_{x}^{\infty} \frac{e^{-u}}{u} d u$

Figure 2 shows the temporal changes in temperature of sediment calculated using Eqs. $(2,3)$ for five models with various combinations of model parameters (Table 1). To focus on the effects of two thermal properties $\left(K_{s}\right.$ and $\left.\rho_{s} c_{s}\right)$ on the change in temperature, the other three parameters $\left(r, q\right.$, and $\left.t_{0}\right)$ are set as fixed constants in the calculations. Temporal changes in the temperature of sediment depend strongly on the thermal properties of the sediment: higher thermal conductivity produces a 

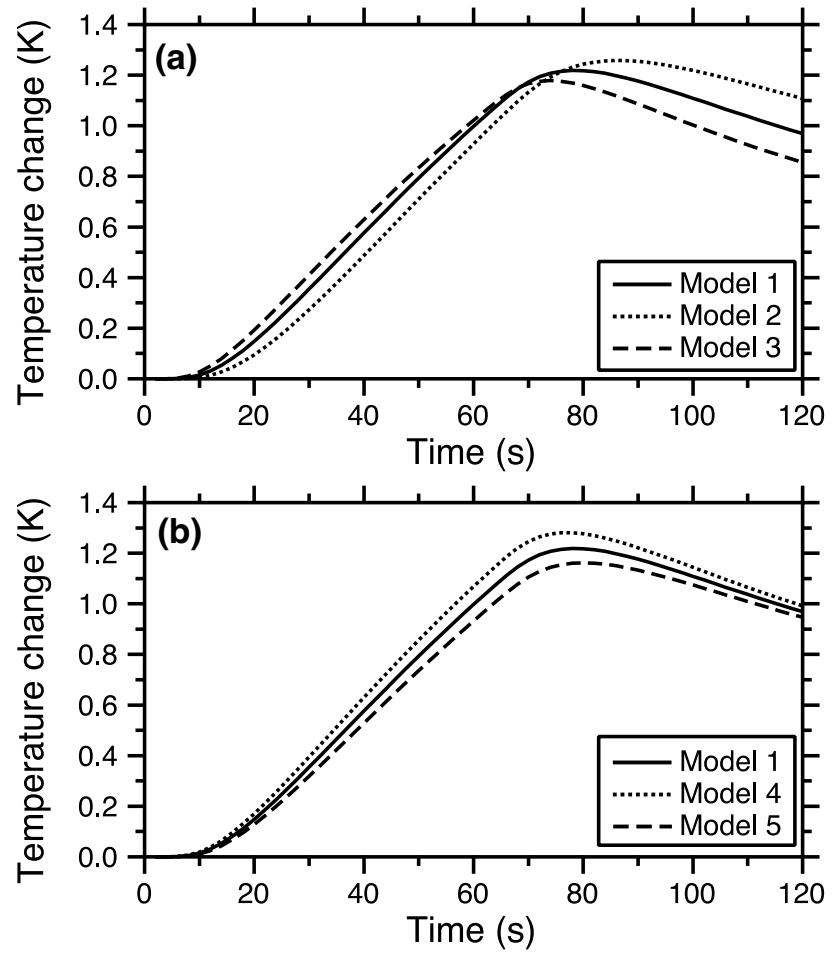

Fig. 2 Plots of temperature changes with time calculated using Eqs. (2, 3). Model parameters used for the calculations are listed in Table 1. a Temperature changes calculated with various values of thermal conductivity. A constant value of heat capacity is assumed. $\mathbf{b}$ Temperature changes calculated with various values of heat capacity. A constant value of thermal conductivity is assumed

Table 1 Model parameters for calculating temperature changes in Fig. 2

\begin{tabular}{llllll}
\hline & $K_{s}(\mathrm{~W} / \mathrm{m} \cdot \mathrm{K})$ & $\begin{array}{l}\rho_{s} c_{s}\left(10^{6} \mathrm{~J} /\right. \\
\left.\mathrm{m}^{3} \cdot \mathrm{K}\right)\end{array}$ & $r(\mathrm{~m})$ & $q(\mathrm{~J} / \mathrm{m} \cdot \mathrm{s})$ & $t_{0}(\mathrm{~s})$ \\
\hline Model 1 & 0.9 & 3.5 & 0.006 & 24.0 & 60 \\
Model 2 & 0.7 & 3.5 & 0.006 & 24.0 & 60 \\
Model 3 & 1.1 & 3.5 & 0.006 & 24.0 & 60 \\
Model 4 & 0.9 & 3.3 & 0.006 & 24.0 & 60 \\
Model 5 & 0.9 & 3.7 & 0.006 & 24.0 & 60 \\
\hline
\end{tabular}

temperature change of smaller amplitude and the appearance of the maximum value in a shorter time (Fig. 2a). In contrast, higher heat capacity results in a temperature change of smaller amplitude and a delayed appearance of the maximum value (Fig. 2b).

In the present study, we first estimated the thermal conductivity and heat capacity of sediment from temperature data obtained by a dual-needle probe device by applying
Bayesian inversion (Tarantola and Valette 1982; Tarantola 2005) (see "Appendix" section), and then calculated thermal diffusivity of the sediment from the estimated thermal conductivity and heat capacity using Eq. (1).

\section{Models of physical and thermal properties of marine sediment}

Several empirical formulae for relationships between two physical properties of marine sediment have been proposed: sound velocity and density (Hamilton 1978), sound velocity and thermal conductivity (Horai 1982), and thermal conductivity and other thermal properties (Von Herzen and Maxwell 1959; Hyndman et al. 1979; Goto and Matsubayashi 2008). Empirical formulae for relationships between thermal properties and the porosity and volume fraction of constituent minerals for marine sediments have also been investigated (Kinoshita 1994; Villinger et al. 1994; Goto and Matsubayashi 2009). Because these relationships are each expressed by a simple formula, they are useful for estimating unknown properties from known properties.

In this section, we briefly describe the existing models of density and thermal properties (thermal conductivity, heat capacity, specific heat, and thermal diffusivity) as a function of porosity and volume fraction of minerals composing ordinary marine sediment. We use these models to subsequently estimate grain density and grain thermal properties of mud-dominant sediment in the Joetsu Basin.

\section{Density model}

The density of a medium is a scalar quantity. The bulk density of seawater-saturated marine sediment $\rho_{s}$ is represented by the simple arithmetic mean formula

$\rho_{s}=\phi \rho_{w}+(1-\phi) \rho_{g}$

where $\phi$ is the fractional porosity, $\rho_{w}$ is the density of seawater that fills pore spaces in the sediment, and $\rho_{g}$ is the density of the sediment grain. If the sediment grain is composed of an $\mathrm{N}$-mineral component aggregate, the grain density is given by

$\rho_{g}=\sum_{j=1}^{N} V_{j} \rho_{j} \quad\left(\sum_{j=1}^{N} V_{j}=1\right)$

where $\rho_{j}$ and $V_{j}$ denote the density and volume fraction of the $j$-th mineral.

\section{Thermal conductivity model}

The thermal conductivity of sediments may be anisotropic, depending in particular on bedding orientation. 
Unconsolidated water-saturated sediment, however, can be treated as an aggregate composed of sediment grains with both random orientation and random distribution. The thermal conductivity of the sediment can then be satisfactorily modeled by the geometric mean (Woodside and Messmer 1961)

$K_{s}=K_{w}^{\phi} K_{g}^{1-\phi}$,

where $K_{w}$ is the thermal conductivity of seawater that fills pore spaces in the sediment and $K_{g}$ is the thermal conductivity of the sediment grain. This model was generalized for the thermal conductivity of $N$-mineral component aggregate (Drury and Jessop 1983) as

$K_{g}=\prod_{j=1}^{N} K_{j}^{V_{j}} \quad\left(\sum_{j=1}^{N} V_{j}=1\right)$.

where $K_{j}$ and $V_{j}$ represent the thermal conductivity and volume fraction of the $j$-th mineral.

\section{Heat capacity and specific heat models}

Heat capacity is a scalar quantity. The heat capacity of marine sediment $\rho_{s} c_{s}$, which can be treated as an aggregate composed of two-phase components of solid and fluid, can be modeled by the arithmetic mean formula (García et al. 1991)

$\rho_{s} c_{s}=\phi \rho_{w} c_{w}+(1-\phi) \rho_{g} c_{g}$,

where $\rho_{w}, c_{w}$, and $\rho_{w} c_{w}$ denote the density, specific heat, and heat capacity, respectively, of seawater that fills pore spaces in the sediment, and $\rho_{g}, c_{g}$, and $\rho_{g} c_{g}$ represent the density, specific heat, and heat capacity, respectively, of the sediment grain. The grain heat capacity of marine sediment $\rho_{g} c_{g}$ as an aggregate composed of $N$-mineral components can be modeled by the arithmetic mean formula (Drury et al. 1984)

$\rho_{g} c_{g}=\sum_{j=1}^{N} V_{j} \rho_{j} c_{j} \quad\left(\sum_{j=1}^{N} V_{j}=1\right)$.

where $\rho_{j}, c_{j}, \rho_{j} c_{j}$, and $V_{j}$ represent respectively the density, specific heat, heat capacity, and volume fraction of the $j$-th mineral.

Specific heat is also a scalar quantity. Using Eqs. $(5,9)$, the specific heat of seawater-saturated sediment $c_{s}$ is expressed by the following non-linear function:

$c_{s}=\frac{\rho_{s} c_{s}}{\rho_{s}}=\frac{\phi \rho_{w} c_{w}+(1-\phi) \rho_{g} c_{g}}{\phi \rho_{w}+(1-\phi) \rho_{g}}$.

From Eqs. $(6,10)$, the specific heat of marine sediment grain $c_{g}$ as an aggregate of $N$-mineral components is given by $c_{g}=\frac{\rho_{g} c_{g}}{\rho_{g}}=\frac{\sum_{j=1}^{N} V_{j} \rho_{j} c_{j}}{\sum_{j=1}^{N} V_{j} \rho_{j}} \quad\left(\sum_{j=1}^{N} V_{j}=1\right)$.

\section{Thermal diffusivity model}

As with thermal conductivity, the thermal diffusivity of sediments may be anisotropic, and depend in particular on bedding orientation. Unconsolidated water-saturated sediment can, however, be treated as an aggregate composed of grains of sediment with both random orientation and distribution. Thermal diffusivity of marine sediment can thus be modeled by using Eqs. $(1,7,9)$ as

$\kappa_{s}=\frac{K_{w}^{\phi} K_{g}^{1-\phi}}{\phi \rho_{w} c_{w}+(1-\phi) \rho_{g} c_{g}}$.

Goto and Matsubayashi (2009) rewrote the above formula as

$\kappa_{s}=f(\beta, \phi) \kappa_{w}^{\phi} \kappa_{g}^{1-\phi}$,

where

$f(\beta, \phi)=\frac{\beta^{\phi}}{1+(\beta-1) \phi}$

$\beta=\frac{\rho_{w} c_{w}}{\rho_{g} c_{g}}$

Equation (14) shows that thermal diffusivity of unconsolidated marine sediment is expressed by the geometric mean model including the correction function $f(\beta, \phi)$.

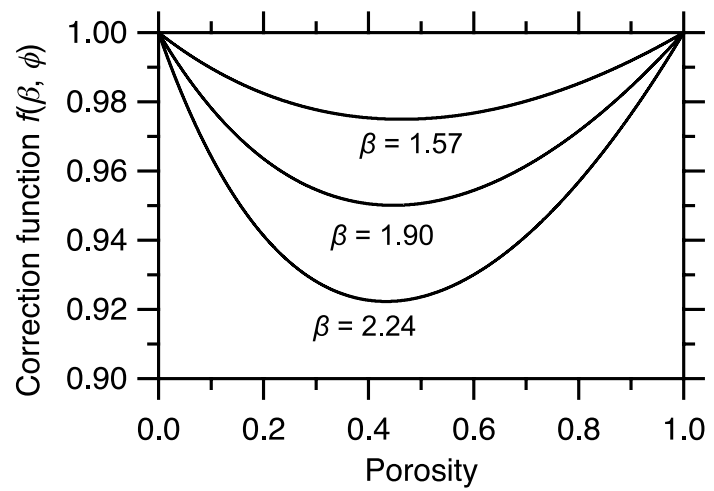

Fig. 3 Plots of calculated results for $f(\beta, \phi)$ versus porosity $\phi$. The $\beta$ values were calculated using the heat capacity of seawater and the maximum, minimum, and mean values of the heat capacity of sediment-constituent minerals in Table 2 using Eq. (16) 
Table 2 Physical and thermal properties of seawater and major and minor sedimentconstituent minerals

\begin{tabular}{llllll}
\hline Mineral & $\begin{array}{l}\text { Density }\left(10^{3}\right. \\
\left.\mathrm{kg} / \mathrm{m}^{3}\right)\end{array}$ & $\begin{array}{l}\text { Thermal conduc- } \\
\text { tivity }(\mathrm{W} / \mathrm{m} \cdot \mathrm{K})\end{array}$ & $\begin{array}{l}\text { Thermal diffusiv- } \\
\text { ity }\left(10^{-6} \mathrm{~m}^{2} / \mathrm{s}\right)\end{array}$ & $\begin{array}{l}\text { Specific heat } \\
\left(10^{3} \mathrm{~J} / \mathrm{kg} \cdot \mathrm{K}\right)\end{array}$ & $\begin{array}{l}\text { Heat capac- } \\
\text { ity }\left(10^{6} \mathrm{~J} /\right. \\
\left.\mathrm{m}^{3} \cdot \mathrm{K}\right)\end{array}$ \\
\hline Quartz & $2.648^{\mathrm{a}}$ & $7.69^{\mathrm{b}}$ & $3.92^{\mathrm{i}}$ & $0.741^{\mathrm{c}}$ & $1.96^{\mathrm{i}}$ \\
Orthoclase & $2.570^{\mathrm{a}}$ & $2.32^{\mathrm{b}}$ & $1.28^{\mathrm{i}}$ & $0.707^{\mathrm{c}}$ & $1.82^{\mathrm{i}}$ \\
Albite & $2.620^{\mathrm{a}}$ & $2.14^{\mathrm{b}}$ & $1.05^{\mathrm{i}}$ & $0.776^{\mathrm{c}}$ & $2.03^{\mathrm{i}}$ \\
Anorthite & $2.760^{\mathrm{a}}$ & $1.68^{\mathrm{b}}$ & $0.817^{\mathrm{i}}$ & $0.745^{\mathrm{c}}$ & $2.06^{\mathrm{i}}$ \\
Calcite & $2.710^{\mathrm{a}}$ & $3.59^{\mathrm{b}}$ & $1.62^{\mathrm{i}}$ & $0.820^{\mathrm{c}}$ & $2.22^{\mathrm{i}}$ \\
Muscovite & $2.831^{\mathrm{a}}$ & $2.32^{\mathrm{b}}$ & $1.03^{\mathrm{f}}$ & $0.796^{\mathrm{i}}$ & $2.25^{\mathrm{i}}$ \\
Illite & $2.660^{\mathrm{a}}$ & $1.85^{\mathrm{d}}$ & $0.861^{\mathrm{i}}$ & $0.808^{\mathrm{e}}$ & $2.15^{\mathrm{i}}$ \\
Smectite (mont- & $2.608^{\mathrm{a}}$ & $1.88^{\mathrm{d}}$ & $0.907^{\mathrm{i}}$ & $0.795^{\mathrm{e}}$ & $2.07^{\mathrm{i}}$ \\
$\quad$ & & & & \\
morillonite $)$ & & & $2.25^{\mathrm{f}}$ & $0.818^{\mathrm{i}}$ & $2.29^{\mathrm{i}}$ \\
Chlorite & $2.800^{\mathrm{a}}$ & $5.15^{\mathrm{b}}$ & $7.40^{\mathrm{i}}$ & $0.518^{\mathrm{g}}$ & $2.60^{\mathrm{i}}$ \\
Pyrite & $5.011^{\mathrm{a}}$ & $19.21^{\mathrm{b}}$ & $0.146^{\mathrm{h}}$ & $3.993^{\mathrm{h}}$ & $4.093^{\mathrm{i}}$ \\
Seawater & $1.025^{\mathrm{h}}$ & $0.596^{\mathrm{h}}$ & & &
\end{tabular}

a Johnson and Olhoeft (1984)

${ }^{\mathrm{b}}$ Horai (1971)

${ }^{c}$ Drury et al. (1984)

${ }^{\mathrm{d}}$ Brigaud and Vasseur (1989)

${ }^{\text {e}}$ Skauge et al. (1983)

${ }^{\mathrm{f}}$ Drury (1987)

${ }^{g}$ Robie and Hemingway (1995)

${ }^{\text {h}}$ Kaye and Laby (1995)

${ }^{\mathrm{i}}$ Calculated from other properties
The correction function $f(\beta, \phi)$ in Eq. (14) depends on the porosity of the sediment $\phi$ and the ratio of the heat capacity of seawater to the heat capacity of the sediment grain $\beta$. Figure 3 shows plots of $f(\beta, \phi)$ versus porosity $\phi$. In the calculations of $f(\beta, \phi)$, three values of $\beta$, which are calculated from heat capacity of seawater and the maximum, minimum, and mean values of heat capacity of minerals listed in Table 2, were used.

As can be seen in Table 2, the heat capacity values of major and minor sedimentary minerals are similar. Using this property, Goto and Matsubayashi (2009) indicated that the grain thermal diffusivity of $N$-mineral component aggregate sediment can be approximated using a simple geometric mean model in the form

$$
\begin{aligned}
\kappa_{g}= & \frac{K_{g}}{\rho_{g} c_{g}}=\frac{\prod_{j=1}^{N} K_{j}^{V_{j}}}{\sum_{j=1}^{N} V_{j} \rho_{j} c_{j}}=\frac{\left(\prod_{j=1}^{N}\left(\rho_{j} c_{j}\right)^{V_{j}}\right)\left(\prod_{j=1}^{N} \kappa_{j}^{V_{j}}\right)}{\sum_{j=1}^{N} V_{j} \rho_{j} c_{j}} \\
& \approx \prod_{j=1}^{N} \kappa_{j}^{V_{j}}\left(\sum_{j=1}^{N} V_{j}=1\right) .
\end{aligned}
$$

\section{Measurements}

\section{Sediment core samples recovered in the Joetsu Basin}

In June 2010, the MD179 research cruise was conducted using the R/V Marion Dufresne to investigate the mechanism of gas hydrate formation in sediment of relatively shallow depth below the seafloor of the Joetsu Basin. During this cruise, sediment cores were recovered using the giant piston corer system with a core barrel of $20-50 \mathrm{~m}$ in length. Figure 1 shows the location of the stations where samples were recovered to measure the physical and thermal properties. The sediments recovered at these stations consist of dark- and light-colored silty mud with several intercalated volcanic ash layers (Kakuwa et al. 2013a, b).

Stations MD179-3296 and MD179-3304 were located in pockmarks on the Umitaka Spur. These pockmarks are within the acoustic blanking zone observed in the sub-bottom profiler. A void with soupy sediment was observed at a depth of ca. $12.5 \mathrm{~m}$ below the seafloor of the sediment core at Station MD179-3296, indicating the existence of gas hydrate that dissociated during the recovery (Kakuwa et al. 2013a). No indication of the existence of gas hydrate 
was observed in the sediment core recovered at Station MD179-3304. Sediment cores with no indication of gas hydrate were recovered at Stations MD179-3299 and MD179-3301 on the eastern flank of the Umitaka Spur. Station MD179-3312 was located on a NW-SE trending ridge. This station was selected as one of two reference stations for the Joetsu Basin during the cruise. Sediment core with no indication of gas hydrate was recovered at this site. Two sediment cores were recovered from the basin floor of the Joetsu Basin (Stations MD179-3308 and MD1793313). The sediment core recovered at Station MD1793308 had voids with soupy sediment at three depths (ca. 8.7, 15.9, and $21.7 \mathrm{~m}$ below seafloor), indicating the presence of gas hydrate that dissociated during the recovery at those depths (Kakuwa et al. 2013a). No indication of gas hydrate was observed in the sediment samples at Station MD179-3313. This station was selected as another reference station for the Joetsu Basin. One sediment sample was recovered on the eastern flank of the northern Joetsu Knoll (Station MD179-3320G). For sediment core recovery at this station, the piston corer system was used as a gravity corer. Recovered sediment core showed no indication of gas hydrate.

\section{Measurements of thermal properties of marine sediment}

Thermal properties of sediment samples recovered during the MD179 cruise were measured onboard with the thermal properties analyzer KD2 Pro (Decagon Devices, Inc., Pullman, WA, USA). The sensor we used was the dual-needle probe-sensor $\mathrm{SH}-1$, which has one probe to heat the material and another probe to measure the temperature of the material. The distance between these probes was $6 \mathrm{~mm}$.

Measurements of the thermal properties were conducted as follows. First, recovered samples were sectioned into $1.5 \mathrm{~m}$-lengths and left horizontally to allow thermal equilibration. Then the dual-needle probe-sensor SH-1 was inserted into the bottom side of the cross-section of the core. After thermal equilibration of the probes and sediment was attained, thermal property measurements were begun. Changes in temperature of the sediment were recorded for $120 \mathrm{~s}$ at a sampling interval of $2 \mathrm{~s}$. For the first $60 \mathrm{~s}$, the heating probe provided output heat at a constant rate $(19-30 \mathrm{~J} / \mathrm{s} \cdot \mathrm{m})$, and was then stopped. Two conditions were introduced to enable measuring of the thermal properties: (a) that the sediment core had not been disturbed by dissociation of gas hydrate during the core recovery and (b) that the cross-section of the core had not been disturbed by handling.

\section{Measurements of physical properties}

The physical properties (porosity and bulk density) of the sediment were determined from sediment sub-samples for headspace gas analysis (Hachikubo et al. 2015). The sub-samples were collected from the topside of the crosssection of the $1.5 \mathrm{~m}$-long cores. Physical properties were measured with a pycnometer in a laboratory as a shorebased study after the end of the MD179 cruise (Kataoka and Matsumoto 2012). The same conditions that were applied to measure the thermal properties were also applied to measure the physical properties.

\section{Results}

\section{Physical and thermal properties of mud-dominant sediment}

In this study, the thermal conductivity and heat capacity of sediment were inverted from temperature data recorded by the dual-needle probe by applying Bayesian inversion (see "Appendix" section). Using these two thermal properties, the thermal diffusivity of the sediment was then calculated using Eq. (1). If physical properties of the sediment, measured at the same cross-section of the core where thermal properties were measured, were available, then the specific heat of the sediment was
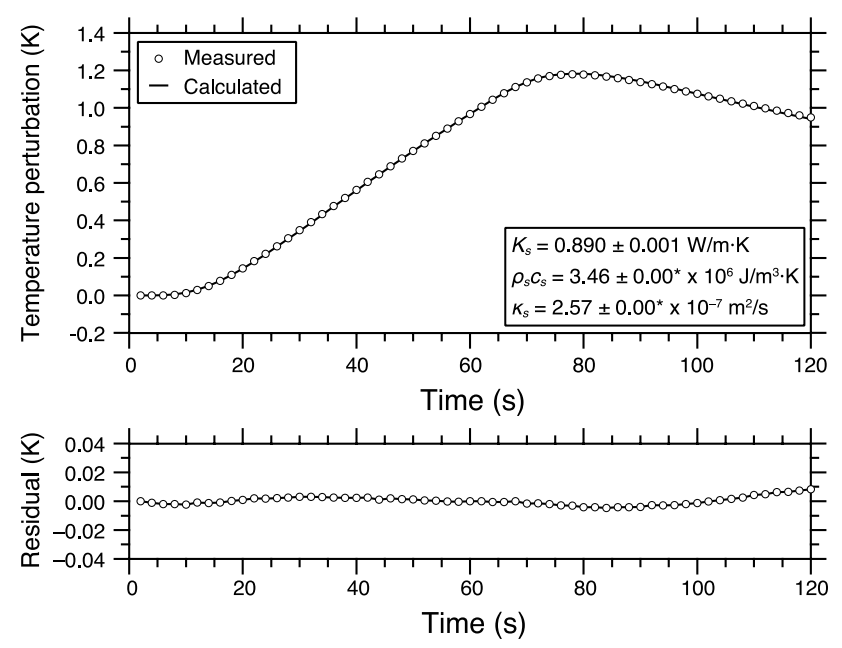

Fig. 4 Example of plots of measured and calculated temperature perturbations for the best estimates of thermal properties for mud-dominant sediment at a depth of $12.06 \mathrm{~m}$ below the seafloor at Station MD179-3313 (top). Residual temperatures between the measured and calculated temperatures are also plotted (bottom). *Error bounds for heat capacity and thermal diffusivity were estimated to be less than $0.01 \times 10^{6} \mathrm{~J} / \mathrm{m}^{3} \cdot \mathrm{K}$ and less than $0.01 \times 10^{-7} \mathrm{~m}^{2} / \mathrm{s}$, respectively 
Fig. 5 Vertical distribution of measured physical and thermal properties of mud-dominant sediment in the Joetsu Basin. $\phi$ porosity, $\rho_{s}$ bulk density, $K_{s}$ thermal conductivity, $\kappa_{s}$ thermal diffusivity, $\rho_{s} c_{s}$ heat capacity, $c_{s}$ specific heat

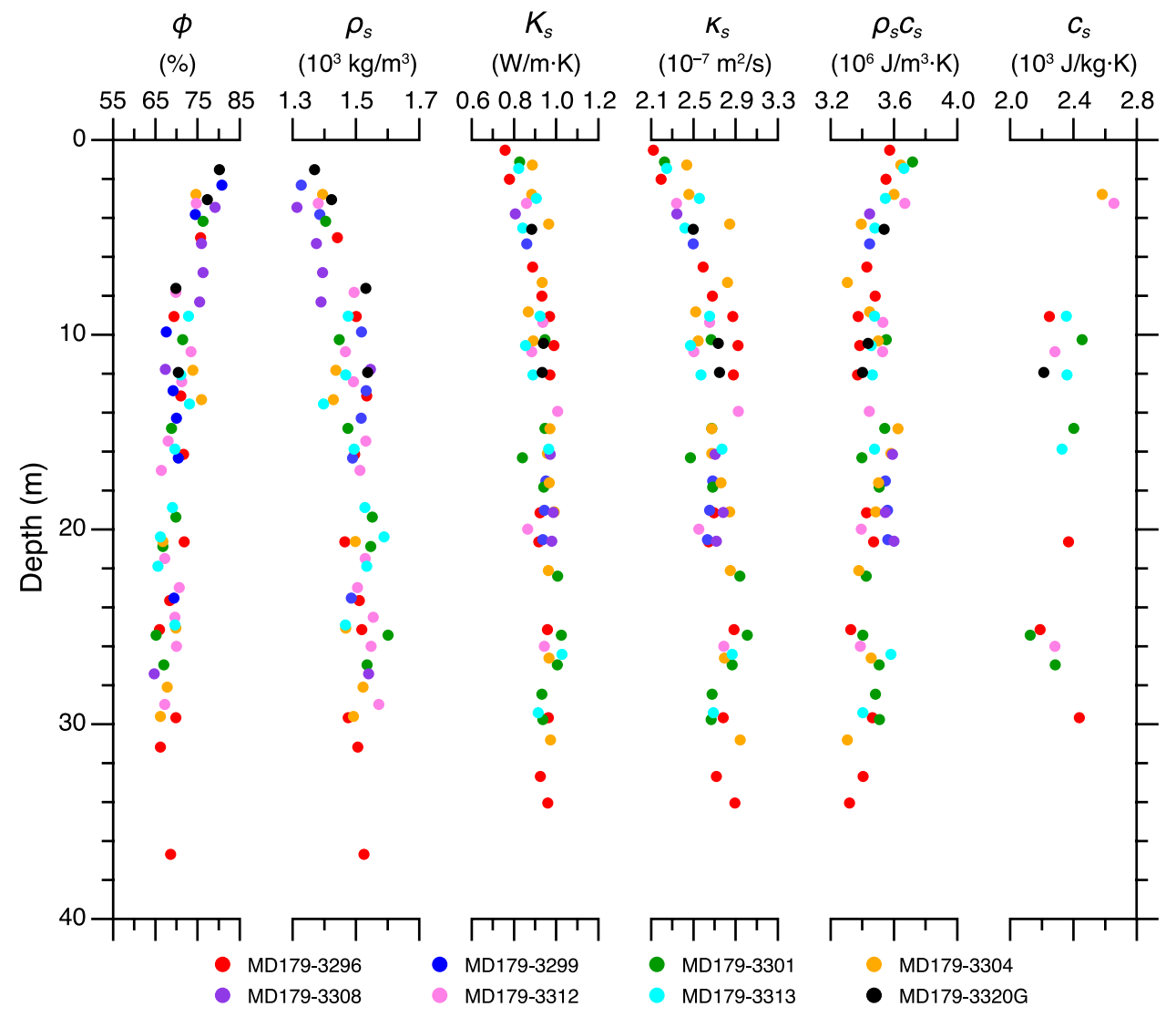

calculated from the heat capacity and bulk density of the sediment.

Figure 4 shows an example of the inverted results of thermal properties of the mud-dominant sediment in the Joetsu Basin. Temperatures calculated from inverted thermal properties fit well with the measured temperatures. For all inversion results, the residual temperatures between measured and calculated temperatures are within $\pm 0.02 \mathrm{~K}$.

Figure 5 shows the vertical distributions of physical and thermal properties of sediment recovered from eight stations, indicating that no differences according to station are seen. We successfully obtained 61 measurements for physical properties and 62 for thermal properties, except for specific heat. For specific heat, 16 measurements were obtained. Hereafter, we treat physical and thermal property data obtained at the eight stations as a single data set.

The porosity of the sediment decreases exponentially with increasing depth from the seafloor because of the compaction effect of the sediment. Vertical distributions of heat capacity and specific heat of the sediment show a positive correlation with that of porosity. In contrast, the vertical distributions of bulk density, thermal conductivity, and thermal diffusivity of the sediment have a negative correlation with that of porosity. Similar vertical distribution patterns for physical and thermal properties were observed for the mud-dominant sediment recovered from the eastern flank of the Juan de Fuca Ridge (Goto and Matsubayashi 2009).

\section{Grain density and grain thermal properties of marine sediment}

We estimated density and four thermal properties of sediment grain for the mud-dominant sediment in the Joetsu Basin from measured physical and thermal properties of the sediment by applying the models of density and thermal properties explained above. Grain density and thermal properties can be estimated by fitting the models of physical and thermal properties to the plots of the bulk density and thermal properties against porosity and extrapolating the fitting results. Bulk density and thermal property data with a wide range of porosity values are required for accurate estimations of their grain properties. In particular, the non-linear relationships of thermal conductivity, thermal diffusivity, and specific heat to porosity impede the accurate estimation of the grain properties of sediment with a limited range of porosity values. The porosity data on the mud-dominant sediment used for this study, in the range of $65-80 \%$, are insufficient to estimate the grain density and grain thermal properties accurately through extrapolation. 
Goto and Matsubayashi (2009) estimated the grain thermal properties for clay and sand (identified as sand turbidite originating from North America) from porosity and thermal property data obtained at Site 1026 of the Ocean Drilling Program (ODP) Leg 168 (Shipboard Scientific Party 1997) and Site U1301 of the Integrated Ocean Drilling Program (IODP) Expedition 301 (Expedition 301 Scientists 2005) in the eastern flank of the Juan de Fuca Ridge (Site 1026 is located 1-2 km north of Site U1301 along the same basement ridge). The numbers of pairs of porosity and thermal properties at those sites were limited (46 pairs for clay and 6 pairs for sand). Furthermore, the range of porosity values for the sediments was limited (40-80\% for clay and $37-45 \%$ for sand). In the calculation of grain thermal conductivity, Goto and Matsubayashi first estimated grain thermal conductivity from each pair of measured thermal conductivity and porosity using the thermal conductivity model. Subsequently, the mean value of the estimated grain thermal conductivity values was calculated. Other grain thermal properties were estimated by the same calculation procedure.

For estimations of grain density and grain thermal properties of mud-dominant sediment in the present study, we applied the calculation procedure of Goto and Matsubayashi (2009). Table 3 lists the results of grain property estimates for mud-dominant sediment in the Joetsu Basin.

Figure 6 shows plots of bulk density and four thermal properties against porosity for mud-dominant sediment in the Joetsu Basin. The measured relationships of physical and thermal properties to porosity show a good fit with the models of estimated grain properties.

The grain thermal diffusivity plotted in Fig. 6e was calculated using Eq. (14) with $\beta=2.03$ calculated from the estimated grain heat capacity of the mud-dominant sediment $\left(2.02 \times 10^{6} \mathrm{~J} / \mathrm{m}^{3} \cdot \mathrm{K}\right)$ and the heat capacity of seawater $\left(4.093 \times 10^{6} \mathrm{~J} / \mathrm{m}^{3} \cdot \mathrm{K}\right)$. The estimated grain thermal diffusivity is $1.36 \pm 0.13 \times 10^{-6} \mathrm{~m}^{2} / \mathrm{s}$, which is in good agreement
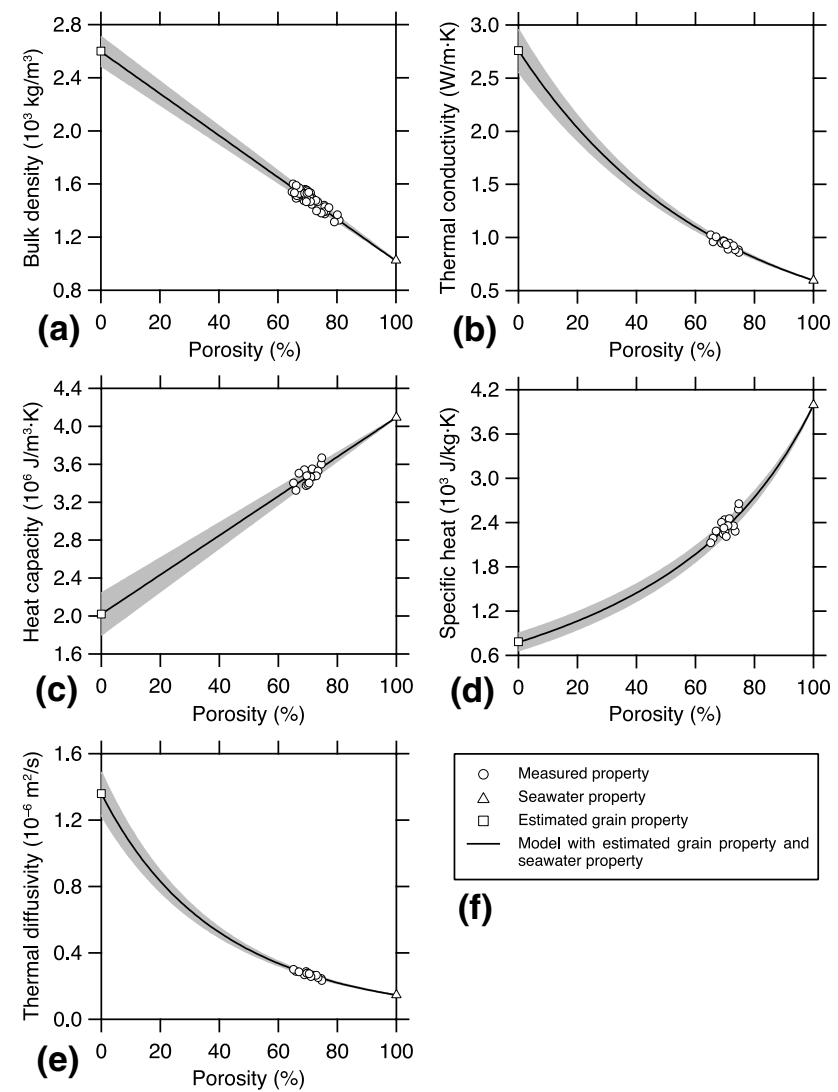

(f)

Fig. 6 Relationships between bulk density and porosity, and between thermal properties and porosity, for mud-dominant sediment in the Joetsu Basin. Grain properties of the sediment estimated from the measured properties are plotted (open square). Density and thermal properties of seawater are also plotted (open triangle). The graycolored interval in each plot indicates the standard deviation for the solid lines and curves that were calculated using the estimated grain properties and the models of physical and thermal properties. a Bulk density versus porosity. b Thermal conductivity versus porosity. $\mathbf{c}$ Heat capacity versus porosity. d Specific heat versus porosity. The grain specific heat was calculated from estimated grain density and heat capacity. e Thermal diffusivity versus porosity. The grain thermal diffusivity was calculated using Eq. (14) with $\beta=2.03$. f Graph legends for plots (a-e)

Table 3 Comparison of grain density and thermal properties of mud-dominant and sandy sediments

\begin{tabular}{|c|c|c|c|c|c|}
\hline \multirow[t]{3}{*}{ Physical and thermal properties } & \multirow{3}{*}{$\begin{array}{l}\text { Joetsu Basin } \\
\text { Mud-dominant } \\
\text { Measurement-based }\end{array}$} & \multicolumn{4}{|c|}{ Eastern flank of Juan de Fuca Ridge } \\
\hline & & \multicolumn{2}{|l|}{ Mud-dominant } & \multicolumn{2}{|l|}{ Sandy } \\
\hline & & Measurement-based & Mineralogy-based & Measurement-based & Mineralogy-based \\
\hline Grain density $\left(10^{3} \mathrm{~kg} / \mathrm{m}^{3}\right)$ & $2.60 \pm 0.11$ & $2.72 \pm 0.11^{\mathrm{a}}$ & $2.73 \pm 0.04^{\mathrm{a}}$ & $2.70 \pm 0.07^{\mathrm{a}}$ & $2.68 \pm 0.02^{\mathrm{a}}$ \\
\hline Grain thermal conductivity $(\mathrm{W} / \mathrm{m} \cdot \mathrm{K})$ & $2.76 \pm 0.20$ & $2.99 \pm 0.81^{\mathrm{b}}$ & $3.40 \pm 0.15^{\mathrm{b}}$ & $3.54 \pm 0.46^{\mathrm{b}}$ & $3.59 \pm 0.28^{b}$ \\
\hline Grain thermal diffusivity $\left(10^{-6} \mathrm{~m}^{2} / \mathrm{s}\right)$ & $1.36 \pm 0.13^{\mathrm{c}}$ & $1.41 \pm 0.54^{\mathrm{b}}$ & $1.64 \pm 0.07^{\mathrm{b}}$ & $1.55 \pm 0.25^{\mathrm{b}}$ & $1.78 \pm 0.15^{\mathrm{b}}$ \\
\hline Grain heat capacity $\left(10^{6} \mathrm{~J} / \mathrm{m}^{3} \cdot \mathrm{K}\right)$ & $2.02 \pm 0.22$ & $2.25 \pm 0.37^{\mathrm{b}}$ & $2.07 \pm 0.01^{\mathrm{b}}$ & $2.38 \pm 0.11^{\mathrm{b}}$ & $2.02 \pm 0.02^{\mathrm{b}}$ \\
\hline Grain specific heat $\left(10^{3} \mathrm{~J} / \mathrm{kg} \cdot \mathrm{K}\right)$ & $0.786 \pm 0.109$ & $0.828 \pm 0.137^{\mathrm{b}}$ & $0.758 \pm 0.010^{\mathrm{b}}$ & $0.881 \pm 0.27^{\mathrm{b}}$ & $0.751 \pm 0.08^{\mathrm{b}}$ \\
\hline
\end{tabular}

${ }^{\mathrm{a}}$ Calculated from data presented by Goto and Matsubayashi (2009)

${ }^{\mathrm{b}}$ Goto and Matsubayashi (2009)

${ }^{c}$ Estimated using Eq. (14) with $\beta=2.03$ 
with grain thermal diffusivity $\left(1.38 \pm 0.18 \times 10^{-6} \mathrm{~m}^{2} / \mathrm{s}\right)$ calculated using the definition of thermal diffusivity (Eq. 1).

Grain thermal conductivity and grain thermal diffusivity of sediment depends on the mineral composition of the sediment. Goto and Matsubayashi (2009) estimated grain thermal properties of clay and sand from porosity and thermal property data for the sediments recovered at Site 1026 and at Site U1301 in the eastern flank of the Juan de Fuca Ridge. They also estimated grain thermal properties of clay and sand from the volume fraction of sediment-constituent minerals calculated from the weight-fraction of the minerals for these sediments obtained at Site 1026 (Shipboard Scientific Party 1997). In the present study, the lithology categories 'clay' and 'sand', as classified by Expedition 301 Scientists (2005), are referred to as mud-dominant and sandy sediments, respectively. Hereafter, the grain properties estimated from measured porosity and thermal properties are referred to as 'measurement-based' grain properties, and the grain properties estimated from the volume fraction of the sediment-constituent minerals are referred to as 'mineralogy-based' grain properties.

Table 3 lists the measurement-based and mineralogybased grain densities and four-grain thermal properties for mud-dominant and sandy sediments in the eastern flank of the Juan de Fuca Ridge, along with measurement-based grain density and grain thermal properties for mud-dominant sediment in the Joetsu Basin. For the eastern flank of the Juan de Fuca Ridge, measurementbased grain thermal conductivity and diffusivity values for sandy sediment are greater than those for muddominant sediment. Similar relationships are seen in the mineralogy-based grain thermal conductivity and diffusivity. In the eastern flank of the Juan de Fuca Ridge, sandy sediment contains ca. 10\% higher amount of quartz than mud-dominant sediment (Table 4). As listed in Table 2, quartz has thermal conductivity and diffusivity values that are considerably greater than those of other sediment-composed minerals, except for pyrite (Table 2). Goto and Matsubayashi (2009) therefore concluded that the differences of grain thermal conductivity and diffusivity between mud-dominant and sandy sediments reflect differences in the amount of quartz in these sediments. The mineralogy-based grain thermal conductivity and diffusivity values for mud-dominant sediment are close to the measurement-based ones for sandy sediment in the Juan de Fuca Ridge (Table 3). Goto and Matsubayashi (2009) suggested that either the mud-dominant sediment at Site 1026 contains a higher amount of quartz than that at Site U1301, or some sediment samples categorized as "mud" during the ODP Leg 168 contained sediments categorized as "mixed" lithology, composed of clay and very fine-grained sandy turbidite, during the IODP Expedition 301 (Goto and Matsubayashi 2008).

Grain thermal conductivity and diffusivity for the muddominant sediment in the Joetsu Basin is lower than that for mud-dominant sediment in the eastern flank of the Juan de Fuca Ridge. We suggest that the differences in grain thermal conductivity and diffusivity between these two areas are attributable to the differences in mineral composition and its volume fraction of mud-dominant sediment, probably mainly the amount of quartz.

The value of grain density for mud-dominant sediment in the Joetsu Basin is slightly lower than that for muddominant sediment in the eastern flank of the Juan de Fuca Ridge. Although there are no mineralogical data for muddominant sediment in the Joetsu Basin, we suggest that the difference in sediment grain density for these marine areas is attributable to the difference in mineral composition and its volume fraction of mud-dominant sediment.

The values of grain specific heat and heat capacity for mud-dominant sediment in the Joetsu Basin are similar to those for mud-dominant and sandy sediments in the eastern flank of the Juan de Fuca Ridge (Table 3), although the measurement-based grain specific heat and heat capacity of the sediments in the two areas have relatively large error margins. As shown in Table 2, values of specific heat and heat capacity for major and minor sediment-constituent minerals, except for the specific heat of pyrite, are similar. Therefore, even though there are differences in mineralogy between the two areas, the grain specific heat and heat capacity of the mud-dominant and sandy sediments in both marine areas show similar values.

Table 4 Mean volume fraction of sediment-constituent minerals of sediments recovered in the eastern flank of the Juan de Fuca Ridge

\begin{tabular}{|c|c|c|c|c|c|c|c|}
\hline \multirow[t]{2}{*}{ Sediment type } & \multicolumn{7}{|c|}{ Volume fraction $(\%)^{\mathrm{a}}$} \\
\hline & Smectite & Mica & Chlorite & Quartz & Feldspar & Calcite & Pyrite \\
\hline Mud-dominant ${ }^{b}$ & $24.29 \pm 4.79$ & $13.14 \pm 3.32$ & $9.90 \pm 2.61$ & $26.29 \pm 3.16$ & $23.29 \pm 3.83$ & $1.02 \pm 1.47$ & $2.07 \pm 1.86$ \\
\hline Sandy ${ }^{\mathrm{c}}$ & $5.78 \pm 3.52$ & $7.51 \pm 4.96$ & $5.98 \pm 1.76$ & $36.07 \pm 6.61$ & $42.92 \pm 8.29$ & $0.84 \pm 0.93$ & $0.89 \pm 0.76$ \\
\hline
\end{tabular}

${ }^{\mathrm{a} C a l c u l a t e d}$ from weight fraction data for sediment-constituent minerals of sediments recovered at Site 1026 obtained during the ODP Leg 168 conducted in the eastern flank of the Juan de Fuca Ridge (Shipboard Scientific Party 1997) by Goto and Matsubayashi (2009)

${ }^{\text {b}}$ Referred to as "mud" by Shipboard Scientific Party (1997)

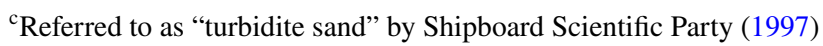




\section{Relationship of thermal diffusivity and heat capacity to thermal conductivity of sediment}

There are limited data on heat capacity and thermal diffusivity of marine sediments, when compared with thermal conductivity data for marine sediments. The relationship between these two thermal properties (heat capacity and thermal diffusivity) and thermal conductivity for marine sediments was developed to deduce these thermal properties from thermal conductivity. Von Herzen and Maxwell (1959) examined data on the thermal conductivity and diffusivity of sediments recovered in the southern Pacific Ocean. They identified the following linear relationship between thermal conductivity and thermal diffusivity:

$\kappa_{s}=3.65 K_{s}-0.7 \quad\left(K_{s}\right.$ in $\mathrm{W} / \mathrm{m} \cdot \mathrm{K}$ and $\kappa_{s}$ in $\left.10^{-7} \mathrm{~m}^{2} / \mathrm{s}\right)$.

Using this relationship, the relationship between heat capacity and thermal conductivity can immediately be obtained as

$\rho_{s} c_{s}=\frac{10 K_{s}}{3.65 K_{s}-0.7} \quad\left(K_{s}\right.$ in $\mathrm{W} / \mathrm{m} \cdot \mathrm{K}$ and $\rho_{s} c_{s}$ in $\left.10^{6} \mathrm{~J} / \mathrm{m}^{3} \cdot \mathrm{K}\right)$.

From the relationship between thermal conductivity and water content of sediment proposed by Ratcliffe (1960) and the grain specific heat of sediment by Bullard (1954), Hyndman et al. (1979) proposed the following empirical formulae for relating thermal diffusivity and heat capacity to thermal conductivity for marine sediment:

$\kappa_{s}=\frac{10 K_{s}}{5.79-3.67 K_{s}+1.016 K_{s}^{2}} \quad\left(K_{s}\right.$ in $\mathrm{W} / \mathrm{m} \cdot \mathrm{K}$ and $\kappa_{s}$ in $\left.10^{-7} \mathrm{~m}^{2} / \mathrm{s}\right)$

$$
\begin{aligned}
\rho_{s} c_{s}= & 5.79-3.67 K_{s}+1.016 K_{s}^{2} \quad\left(K_{s} \text { in } \mathrm{W} / \mathrm{m} \cdot \mathrm{K} \text { and } \rho_{s} c_{s}\right. \\
& \text { in } \left.10^{6} \mathrm{~J} / \mathrm{m}^{3} \cdot \mathrm{K}\right) .
\end{aligned}
$$

In contrast, Goto and Matsubayashi (2008) proposed the following empirical formulae for the relationships among the thermal properties of the mud-dominant sediment on the eastern flank of the Juan de Fuca Ridge and showed that they provided a better fit to the data than the formulae of Hyndman et al. (1979):

$$
\begin{aligned}
\kappa_{s}= & -0.176+2.284 K_{s}+0.763 K_{s}^{2} \quad\left(K_{s} \text { in } \mathrm{W} / \mathrm{m} \cdot \mathrm{K} \text { and } \kappa_{s}\right. \\
& \text { in } \left.10^{-7} \mathrm{~m}^{2} / \mathrm{s}\right)
\end{aligned}
$$

$$
\begin{aligned}
\rho_{s} c_{s}= & \frac{10 K_{s}}{-0.176+2.284 K_{s}+0.763 K_{s}^{2}} \quad\left(K_{s} \text { in } \mathrm{W} / \mathrm{m} \cdot \mathrm{K}\right. \text { and } \\
& \left.\rho_{s} c_{s} \text { in } 10^{6} \mathrm{~J} / \mathrm{m}^{3} \cdot \mathrm{K}\right) .
\end{aligned}
$$
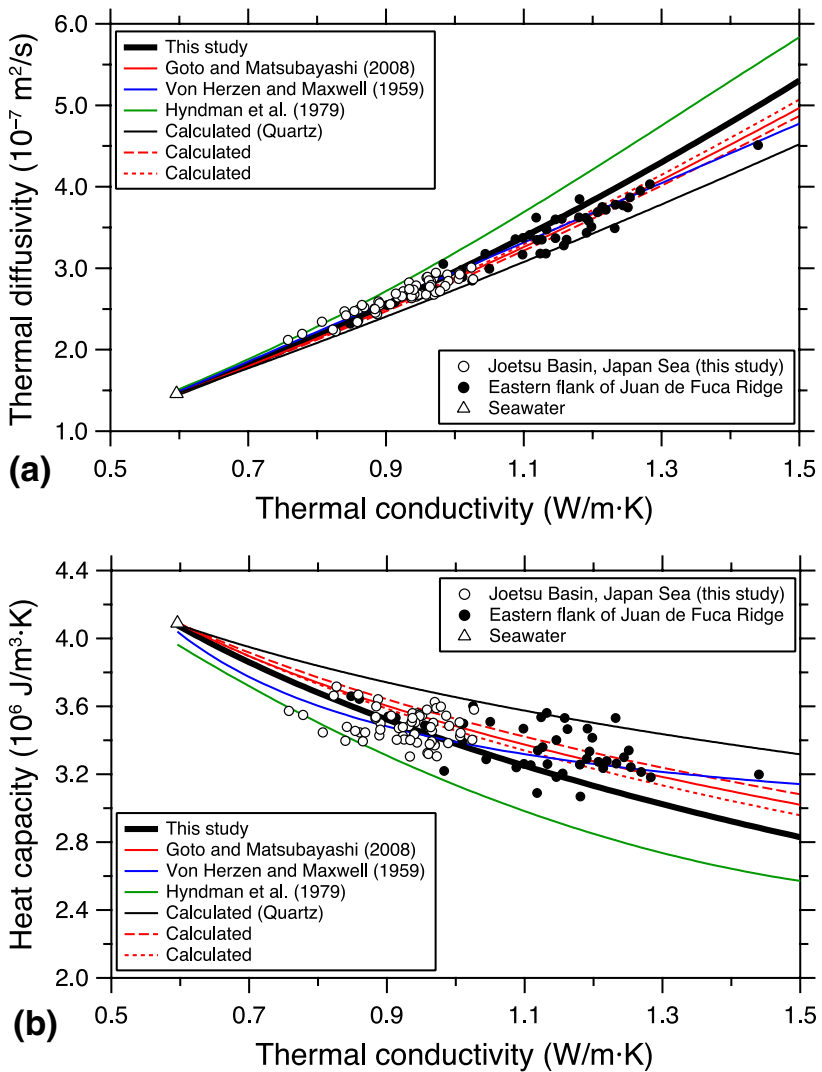

Fig. 7 Relationship between a thermal diffusivity and thermal conductivity and $\mathbf{b}$ heat capacity and thermal conductivity of sediment. Open circles indicate the observed data for mud-dominant sediment in the Joetsu Basin. Closed circles are the observed data for muddominant sediment at Site U1301 from the IODP Expedition 301 in the eastern flank of Juan de Fuca Ridge (Goto and Matsubayashi 2008). The thick black curve is the best-fit relationship for the thermal properties of the sediment in the Joetsu Basin. The red solid curve is the best-fit relationship proposed by Goto and Matsubayashi (2008) for the thermal properties of sediment at Site U1301. The blue and green curves express the relationships between thermal diffusivity and thermal conductivity, and between and heat capacity and thermal conductivity of marine sediments, as proposed by Von Herzen and Maxwell (1959) and Hyndman et al. (1979). Red dashed and dotted curves show these relationships among thermal properties calculated for sediments that contain amounts of quartz 10\% higher and $10 \%$ lower than mud-dominant sediment in the eastern flank of the Juan de Fuca Ridge (Goto and Matsubayashi 2008)

Figure $7 \mathrm{a}, \mathrm{b}$ show plots of thermal diffusivity against thermal conductivity, and of heat capacity against thermal conductivity, respectively, of mud-dominant sediment for the Joetsu Basin in this study and for the Juan de Fuca Ridge (Goto and Matsubayashi 2008). These figures also include curves of the relationships among these thermal properties calculated using the empirical formulae presented by Von Herzen and Maxwell (1959), Hyndman et al. (1979), and Goto and Matsubayashi (2008), and of seawater-saturated quartz calculated using Eqs. (1, 7, 9). The relationships 
among thermal properties calculated for sediments that contains amounts of quartz 10\% higher and 10\% lower than mud-dominant sediment in the eastern flank of the Juan de Fuca Ridge (Goto and Matsubayashi 2008) are plotted as red dashed and dotted curves, respectively.

The best-fit curve depicting the empirical relationship between thermal conductivity and thermal diffusivity of mud-dominant sediment in the Joetsu Basin is given by the following quadratic equation:

$$
\begin{aligned}
\kappa_{s}= & -0.1013+1.977 K_{s}+1.084 K_{s}^{2} \quad\left(K_{s} \text { in } \mathrm{W} / \mathrm{m} \cdot \mathrm{K}\right. \text { and } \\
& \left.\kappa_{s} \text { in } 10^{-7} \mathrm{~m}^{2} / \mathrm{s}\right)
\end{aligned}
$$

Using Eqs. (1, 24), the empirical relationship of heat capacity to thermal conductivity for the sediment is given by

$$
\begin{aligned}
\rho_{s} c_{s}= & \frac{10 K_{s}}{-0.1013+1.977 K_{s}+1.084 K_{s}^{2}} \quad\left(K_{s} \text { in } \mathrm{W} / \mathrm{m} \cdot \mathrm{K}\right. \text { and } \\
& \left.\rho_{s} c_{s} \text { in } 10^{6} \mathrm{~J} / \mathrm{m}^{3} \cdot \mathrm{K}\right) .
\end{aligned}
$$

At the interval of thermal conductivity measured in this study $(0.8-1.05 \mathrm{~W} / \mathrm{m} \cdot \mathrm{K})$, the empirical formulae relating thermal diffusivity to thermal conductivity proposed by Von Herzen and Maxwell (1959) and Goto and Matsubayashi (2008) also fit the observed thermal conductivity and diffusivity data (Fig. 7a), and the observed heat capacity and thermal conductivity data (Fig. 7a) for the Joetsu Basin. The empirical formulae for these relationships proposed by Hyndman et al. (1979) deviates most from the observed thermal properties.

The observed thermal conductivity and diffusivity for sediment in the eastern flank of the Juan de Fuca Ridge is distributed over the high-thermal conductivity side, compared with the curve for sediment in the Joetsu Basin (Fig. 7a). Thermal conductivity and diffusivity of marine sediment depends on the mineral composition of the sediment. Grain thermal conductivity and diffusivity estimated in the previous section suggested that sediment in the eastern flank of the Juan de Fuca Ridge may contain a higher amount of quartz than the Joetsu Basin. The observed relationship of thermal diffusivity to thermal conductivity for the eastern Juan de Fuca Ridge is distributed between the best-fit curve for the Joetsu Basin and the curves calculated for the relationship of seawater-saturated quartz (Fig. 7a). This suggests that the relationship between thermal diffusivity and thermal conductivity for marine sediment may vary with the volume fraction of quartz in the sediment, although there may be some contributions by other minerals with high thermal conductivity, such as chlorite and pyrite.
The heat capacity of marine sediment has little dependence on the volume fraction of minerals because of similar heat capacity values of major and minor sediment-constituent minerals (Table 2). In contrast, thermal diffusivity of marine sediment depends on the mineral composition of the sediment. Observed heat capacity and thermal conductivity data for sediment in the Juan de Fuca Ridge is distributed between the best-fit curve for the Joetsu Basin and the curves calculated for seawater-saturated quartz (Fig. 7b). Similarly to the relationship between thermal diffusivity and conductivity for marine sediment discussed above, the relationship between heat capacity and thermal conductivity for marine sediment appears to depend on the volume fraction of quartz in the sediment, although there may be some contribution by other minerals with high thermal conductivity.

We therefore conclude that extrapolating thermal properties from one area where the relationships among thermal properties have been developed to another area must be done with caution. If similar studies are done in several areas of sediments with mineral composition data, better formulae for thermal property relationships taking into account mineral composition of sediment will be obtained.

\section{Summary}

To investigate thermal properties of mud-dominant sediment in the Joetsu Basin on the eastern margin of the Japan Sea, we measured thermal properties (thermal conductivity, heat capacity, and hence thermal diffusivity) of the sediment by applying the dual-needle probe method. We also measured physical properties (bulk density and porosity) of the sediment. We calculated the specific heat of the sediment at the points on the cores where both thermal and physical properties were measured.

The vertical distribution of measured porosity of the sediment shows a decrease exponentially with increasing depth below the seafloor. The vertical distribution of measured bulk density and thermal properties of the sediment display strong dependence on porosity. Heat capacity and specific heat decrease with increasing depth below the seafloor because both are positively correlated with porosity, while bulk density, thermal conductivity, and thermal diffusivity increase with increasing depth below the seafloor because they are negatively correlated with porosity.

We estimated grain density and grain thermal properties of mud-dominant sediment in the Joetsu Basin by applying the existing models of physical and thermal properties of sediment that express these properties as a function of porosity. The measurement-based grain density and grain thermal properties of mud-dominant 
sediment in the Joetsu Basin were compared with those of mud-dominant and sandy sediments in the eastern flank of the Juan de Fuca Ridge. It was found that grain density, grain thermal conductivity, and grain thermal diffusivity appear to be influenced by the mineral composition of the sediment. Grain thermal conductivity and diffusivity, in particular, appear to depend on the volume fraction of quartz in the sediment. In contrast, grain heat capacity and grain specific heat of the sediment showed less dependency on the volume fraction of the sedimentconstituent minerals because the minerals have similar values for these thermal properties.

We investigated relationships between thermal conductivity and thermal diffusivity and between thermal conductivity and heat capacity, for mud-dominant sediment in the Joetsu Basin, and proposed empirical formulae to express these relationships. Comparison of the empirical formulae proposed in this study with those presented in previous work for sediment in the eastern flank of the Juan de Fuca Ridge showed that these relationships may vary with the volume fraction of quartz, indicating that these relationships have to be investigated in each marine area because the mineral composition of sediment varies according to area. If similar studies are done in several areas of sediments with various mineral compositions, better formulae for the thermal property relationships that take into account mineral composition of sediment will be obtained.

Acknowledgements We are indebted to the captain and crew of R/V Marion Dufresne and the onboard scientists for core sample handling during the MD179 cruise. We thank Osamu Matsubayashi for discussions about the thermal properties of sediment in the Joetsu Basin. We are grateful to Kiichiro Kawamura for discussions about the mineral composition of sediment. This study was financially supported by the MH21 Research Consortium for Methane Hydrate Resources in Japan.

Open Access This article is distributed under the terms of the Creative Commons Attribution 4.0 International License (http:// creativecommons.org/licenses/by/4.0/), which permits unrestricted use, distribution, and reproduction in any medium, provided you give appropriate credit to the original author(s) and the source, provide a link to the Creative Commons license, and indicate if changes were made.

\section{Appendix}

\section{Bayesian inversion scheme}

In this study, the thermal conductivity $K_{s}$ and heat capacity $\rho_{s} c_{s}$ of mud-dominant sediment were inverted from temperatures measured with a dual-needle probe device using Eqs. $(2,3)$. Here the method of inversion used in this study is explained.
We denote unknown parameters $\left(K_{s}\right.$ and $\left.\rho_{s} c_{s}\right)$ by vector $\mathbf{p}$, and temperature data obtained by a dual-needle probe device by $\mathbf{d}_{\mathbf{0}}$. It is important that other parameters $\left(r, q, t_{0}\right)$ in Eqs. $(2,3)$ in the main text are known. The algorithm of the Bayesian inversion of these parameters from the dual-needle probe temperature data determines a model that minimizes the following misfit function (Tarantola and Valette 1982; Tarantola 2005)

$S(\mathbf{p})=\frac{1}{2}\left[\left(\mathbf{g}(\mathbf{p})-\mathbf{d}_{\mathbf{0}}\right)^{\mathbf{T}} \mathbf{C}_{\mathbf{d}}^{-\mathbf{1}}\left(\mathbf{g}(\mathbf{p})-\mathbf{d}_{\mathbf{0}}\right)+\left(\mathbf{p}-\mathbf{p}_{\mathbf{0}}\right)^{\mathbf{T}} \mathbf{C}_{\mathbf{p}}^{-\mathbf{1}}\left(\mathbf{p}-\mathbf{p}_{\mathbf{0}}\right)\right]$,

where $\mathbf{g}(\mathbf{p})$ is the calculated temperature and $\mathbf{p}_{\mathbf{0}}$ is the $a$ priori model parameter. $\mathbf{C}_{\mathbf{d}}$ is the covariance operator of $\mathbf{d}_{\mathbf{0}}$ and $\mathbf{C}_{\mathbf{p}}$ is the covariance operator of $\mathbf{p}_{\mathbf{0}}$. In this study, we applied the following Gauss-Newton iterative scheme to seek plausible model parameters (Tarantola and Valette 1982; Tarantola 2005)

$$
\begin{aligned}
\mathbf{p}_{\mathrm{k}+1}= & \mathbf{p}_{\mathrm{k}}+\left(\mathbf{G}_{\mathbf{k}}^{\mathrm{T}} \mathbf{C}_{\mathrm{d}}^{-1} \mathbf{G}_{\mathrm{k}}+\mathbf{C}_{\mathbf{p}}^{-1}\right)^{-1}\left\{\mathbf{G}_{\mathrm{k}}^{\mathrm{T}} \mathbf{C}_{\mathbf{d}}^{-1}\left[\mathbf{d}_{0}-\mathbf{g}\left(\mathbf{p}_{\mathrm{k}}\right)\right]\right. \\
& \left.-\mathbf{C}_{\mathbf{p}}^{-1}\left(\mathbf{p}_{\mathrm{k}}-\mathbf{p}_{\mathbf{0}}\right)\right\}
\end{aligned}
$$

where $\mathbf{p}_{\mathbf{k}}$ is the estimate of $\mathbf{p}$ at the $k$-th iteration and $\mathbf{G}_{\mathbf{k}}$ is the gradient of the matrix of the calculated temperature with regard to the model parameters

$\mathbf{G}_{\mathbf{k}}=\left(\frac{\partial \mathbf{g}(\mathbf{p})}{\partial \mathbf{p}}\right)_{\mathbf{p}_{\mathbf{k}}}$.

Using the best estimates of thermal conductivity $K_{s}$ and heat capacity $\rho_{s} c_{s}$ of mud-dominant sediment, thermal diffusivity $\kappa_{s}$ of the sediment was calculated using Eq. (1) in the main text.

\section{References}

Aoyama C, Matsumoto R (2009) Acoustic surveys of methane plumes by quantitative echo sounder in Japan Sea and the estimate of the seeping amount of the methane hydrate bubbles. J Geogr 118:156-174 (in Japanese with English abstract)

Brigaud F, Vasseur G (1989) Mineralogy, porosity and fluid control on thermal conductivity of sedimentary rocks. Geophys J 98:525-542

Bristow KL (1998) Measurement of thermal properties and water content of unsaturated sandy soil using dual-probe heat-pulse probes. Agr Forest Meteorol 89:75-84

Bullard EC (1954) The flow of heat through the floor of the Atlantic Ocean. Proc R Soc Lond A 222:408-429

Carslaw HS, Jaeger JC (1959) Conduction of heat in solids, 2nd edn. Oxford University Press, London

de Vries DA (1952) A nonstationary method for determining thermal conductivity of soil in situ. Soil Sci 73:83-90

Drury MJ (1987) Thermal diffusivity of some crystalline rocks. Geothermics 16:105-115 
Drury MJ, Jessop AM (1983) The estimation of rock thermal conductivity from mineral content-An assessment of techniques. Zentralbl Geol Palaeontol 1:35-48

Drury MJ, Allen VS, Jessop AM (1984) The measurement of thermal diffusivity of rock cores. Tectonophysics 103:321-333

Expedition 301 Scientists (2005) Site U1301. In: Fisher AT, Urabe T, Klaus A, The Expedition 301 Scientists (eds) Proceedings of IODP, 301. Integrated Ocean Drilling Program Management International, Inc., College Station. doi:10.2204/iodp. proc.301.106.2005

Freire AFM, Matsumoto R, Santos LA (2011) Structural-stratigraphic control on the Umitaka Spur gas hydrates of Joetsu Basin in the eastern margin of Japan Sea. Mar Petrol Geol 28:1967-1978

García A, Contreras E, Domínguez B (1991) Developments in geothermal energy in Mexico-Part thirty-three. Simultaneous determination of the thermal properties of geothermal drill cores. Heat Recov Syst CHP 11:131-139

Goto S, Matsubayashi O (2008) Inversion of needle-probe data for sediment thermal properties of the eastern flank of the Juan de Fuca Ridge. J Geophys Res 113:B08105. doi:10.1029/200 7JB005119

Goto S, Matsubayashi O (2009) Relations between the thermal properties and porosity of sediments in the eastern flank of the Juan de Fuca Ridge. Earth Planets Space 61:863-870

Gustafsson SE (1991) Transient plane source techniques for thermal conductivity and thermal diffusivity measurements of solid materials. Rev Sci Instrum 62:797-804

Hachikubo A, Yanagawa K, Tomaru H, Lu HL, Matsumoto R (2015) Molecular and isotopic composition of volatiles in gas hydrates and in sediment from the Joetsu Basin, eastern margin of the Japan Sea. Energies 8:4647-4666

Hamamoto H, Yamano M, Goto S (2005) Heat flow measurement in shallow seas through long-term temperature monitoring. Geophys Res Lett 32:L21311. doi:10.1029/2005GL024138

Hamilton EL (1978) Sound velocity-density relations in sea-floor sediments and rocks. J Acoust Soc Am 63:366-377

Hiromatsu M, Matsumoto R, Machiyama H, Satoh M, YK10-08 Shipboard Scientists (2011) High-resolution topographic features of shallow gas hydrate field of Joetsu Basin, eastern margin of Japan Sea. In: Proceedings of the 7th international conference on gas hydrates (ICGH 2011), Edinburgh, Scotland

Hiruta A, Snyder GT, Tomaru H, Matsumoto R (2009) Geochemical constraints for the formation and dissociation of gas hydrate in an area of high methane flux, eastern margin of the Japan Sea. Earth Planet Sci Lett 279:326-339

Horai K (1971) Thermal conductivity of rock-forming minerals. J Geophys Res 76:1278-1308

Horai K (1982) Thermal conductivity of sediments and igneous rocks recovered during Deep Sea Drilling Project Leg 60. In: Hussong DM, Uyeda $S$ et al (eds) Initial reports of the DSDP, 60. United States Government Printing Office, Washington, pp 807-834

Hyndman RD, Davis EE, Wright JA (1979) The measurement of marine geothermal heat flow by a multipenetration probe with digital acoustic telemetry and in situ thermal conductivity. Mar Geophys Res 4:181-205

Johnson GR, Olhoeft GR (1984) Density of rocks and minerals. In: Carmichael RS (ed) CRC handbook of physical properties of rocks, vol III. CRC Press, Boca Raton, pp 1-38

Kakuwa Y et al (2013a) Description of sediments recovered during the cruise of MD179 in the Japan Sea, from Joetsu Knoll to southwest Hokkaido. J Japan Assoc Petrol Technol 78:104-112 (in Japanese with English abstract)

Kakuwa Y et al (2013b) Description of sediments recovered during the cruise of MD179 in the Japan Sea, Umitaka Spur and its surrounding area, off Joetsu. J Japan Assoc Petrol Technol 78:97103 (in Japanese with English abstract)
Kataoka S, Matsumoto R (2012) The physical and mechanical properties of sea-bottom sediments in the eastern margin of Japan Sea by MD179. J Japan Assoc Petrol Technol 77:274-279 (in Japanese with English abstract)

Katayama H, Nakajima T, Ikehara K (1994) Explanatory notes of sedimentological map south of Sado Island. Marine geology map series 44. Geological Survey of Japan, Tsukuba, Japan (in Japanese with English abstract)

Kaye GWC, Laby TH (1995) Tables of physical and chemical constants, 16th edn. Longman, Harlow

Kinoshita M (1994) Estimating of grain thermal conductivity in the turbidite sediment of the Juan de Fuca Ridge. In: Mottl MJ, Davis EE, Fisher AT, Slack JF (eds) Proceedings of the ODP, scientific results, 139. Ocean Drilling Program, Texas A\&M University, College Station, pp 553-558

Kinoshita M, Goto S, Yamano M (1996) Estimation of thermal gradient and diffusivity by means of long-term measurements of subbottom temperatures at western Sagami Bay, Japan. Earth Planet Sci Lett 141:249-258

Lin WR, Fulton PM, Harris RN, Tadai O, Matsubayashi O, Tanikawa W, Kinoshita M (2014) Thermal conductivities, thermal diffusivities, and volumetric heat capacities of core samples obtained from the Japan Trench Fast Drilling Project (JFAST). Earth Planets Space 66:48

Matsumoto R et al (2009) Formation and collapse of gas hydrate deposits in high methane flux area of the Joetsu Basin, eastern margin of Japan Sea. J Geogr 118:43-71 (in Japanese with English abstract)

Matsumoto R, Hiromatsu M, Sato M, YK10-08 Shipboard Scientists (2011) Fluid flow and evolution of gas hydrate mounds of Joetsu Basin, eastern margin of Japan Sea: constraints from high-resolution geophysical survey by AUV. In: Proceedings of the 7th international conference on gas hydrates (ICGH 2011), Edinburgh, Scotland

Monzawa N, Kaneko M, Osawa M (2006) A review of petroleum system in the deep water area of the Toyama Trough to the Sado Island in the Japan Sea, based on the results of the METI Sado Nansei Oki drilling. J Japan Assoc Petrol Technol 71:618-627 (in Japanese with English abstract)

Nakajima T et al (2014) Formation of pockmarks and submarine canyons associated with dissociation of gas hydrates on the Joetsu Knoll, eastern margin of the Sea of Japan. J Asian Earth Sci 90:228-242

Osawa M, Wihardjo LU, Mitsuishi H, Muramoto K, Ishiyama Y (2005) Application for new wireline formation evaluation method to the sandstones of Shiiya Formation in the METI Sado Nansei Oki wells. J Japan Assoc Petrol Technol 70:347-357 (in Japanese with English abstract)

Ratcliffe EH (1960) The thermal conductivities of ocean sediments. J Geophys Res 65:1535-1541

Robie RA, Hemingway BS (1995) Thermodynamic properties of minerals and related substances at $298.15 \mathrm{~K}$ and 1 bar ( $10^{5}$ pascals) pressure and at higher temperatures. U S Geol Surv Bull 2131

Saeki T, Inamori T, Nagakubo S, Ward P, Asakawa E (2009) 3D seismic velocity structure below mounds and pockmarks in the deep water southwest of the Sado Island. J Geogr 118:93-110 (in Japanese with English abstract)

Sass JH, Stone C, Munroe RJ (1984) Thermal conductivity determinations on solid rock - a comparison between a steady-state divided-bar apparatus and a commercial transient line-source device. J Volcanol Geotherm Res 20:145-153

Shipboard Scientific Party (1997) Rough basement transect (site 1026 and 1027). In: Davis EE, Fisher AT, Firth JV et al (eds) Proceedings of the ODP, initial reports, 168. Ocean Drilling Program, Texas A\&M University, College Station, pp 101-160 
Skauge A, Fuller N, Hepler LG (1983) Specific heats of clay minerals: sodium and calcium kaolinites, sodium and calcium montmorillonites, illite, and attapulgite. Thermochim Acta 61:139-145

Tanikawa $\mathrm{W}$ et al (2016) Thermal properties and thermal structure in the deep-water coalbed basin off the Shimokita Peninsula, Japan. Mar Petrol Geol 73:445-461

Tarantola A (2005) Inverse problem theory and methods for model parameter estimation. Society for Industrial and Applied Mathematics, Philadelphia

Tarantola A, Valette B (1982) Generalized nonlinear inverse problems solved using the least squares criterion. Rev Geophys 20:219-232
Villinger HW, Langseth MG, Gröschel-Becker HM, Fisher AT (1994) Estimating in situ thermal conductivity from log data. In: Mottl MJ, Davis EE, Fisher AT, Slack JF (eds) Proceedings of the ODP, scientific results, 139. Ocean Drilling Program, Texas A\&M University, College Station, pp 545-552

Von Herzen RP, Maxwell AE (1959) The measurement of thermal conductivity of deep-sea sediments by a needle-probe method. J Geophys Res 64:1557-1563

Woodside W, Messmer JH (1961) Thermal conductivity of porous media. I. Unconsolidated sands. J Appl Phys 32:1688-1699 